\title{
Multimodality Imaging Based Target Definition of Cervical Lymph Nodes in Precise Limited Field Radiation Therapy (Lfrt) for Nodular Lymphocyte Predominant Hodgkin Lymphoma (Nlphl)
}

\author{
Selcuk Demiral, Ferrat Dincoglan,Omer Sager, Murat Beyzadeoglu \\ Department of Radiation Oncology, University of Health Sciences, Gulhane Medical Faculty, Ankara, Turkey \\ *Corresponding Author: Selcuk Demiral, Department of Radiation Oncology, University of Health \\ Sciences, Gulhane Medical Faculty, Ankara, Turkey
}

\begin{abstract}
Objective: Nodular lymphocyte predominant hodgkin lymphoma (NLPHL) constitutesa distinct and typically indolent subtype of hodgkin lymphoma with favorable therapeutic outcomes. Radiation therapy $(R T)$ plays a major role in management of NLPHL. Irradiation of limited target volumes is an area of active investigation to limit radiation induced toxicities. Nevertheless, accuracy and precision in target definition is of utmost importance in the context of limited field RT (LFRT). Herein, we assess multimodality imaging based target definition of cervical lymph nodes in precise LFRT for NLPHL.
\end{abstract}

Materials and Methods: Incorporation of integrated positron emission tomography (PET)- computed tomography (CT) imaging for target volume determination of NLPHL was evaluated.

Results: Determination of ground truth target volume was performed by board-certified radiation oncologists after meticulous assessment, thorough consideration, collaboration, colleague peer review, and ultimate consensus for actual treatment and for compison purposes. RT delivery was performed by Synergy (Elekta, UK) LINAC with kilovoltage cone beam CT and electronic portal imaging verification capability. Target volume definition by CT-only imaging and by incorporated PET-CT images was assessed with comparative analysis. Ground truth target volume was found to be identical with target volume definition by incorporated PET-CT images.

Conclusion: Multimodality imaging based target volume definition should be considered for radiotherapeutic management of NLPHL with LFRT. Further studies are needed to shed light on this issue.

Keywords: nodular lymphocyte predominant hodgkin lymphoma (NLPHL), limited fieldradiation therapy (LFRT), positron emission tomography (PET)

\section{INTRODUCTION}

Hodgkin lymphoma is a rare subtype of B cell lymphoma [1]. Nodular lymphocyte predominant hodgkin lymphoma (NLPHL) constitutes a distinct and typically indolent subtype of hodgkin lymphoma with favorable therapeutic outcomes [2-5]. Radiation therapy (RT) plays a major role in management of NLPHL. However, active surveillance has even been considered as an initial management strategy for selected patients given the typically indolent disease course and concerns regarding treatment induced toxicities [6]. In the context of RT, several studies have addressed use of different approaches for improving the toxicity profile of irradiation such as dose deescalation and limited field RT (LFRT) [7-12]. Irradiation of limited treatment volumes may serve as a viable method in the context of reduced adverse effects, however, this strategy should be utilized carefully with accurate and precise target definition to avoid any geographical misses which may lead to treatment failure. RT planning for NLPHL is typically based on computed tomography (CT) simulation at treatment position. Incorporation of additional imaging modalities offer great potential for improved target definition. Herein, we assess multimodality imaging based target definition of cervical lymph nodes in precise LFRT for NLPHL.

\section{Materials ANd Methods}

Incorporation of integrated positron emission tomography (PET)-CT imaging for target 
volume determination of NLPHL was evaluated. Either CT-simulation images only or incorporated PET-CT images were utilized for target definition in patients receiving LFRT directed at the cervical lymph nodes for NLPHL management. Ground truth target volume which served as the reference for actual treatment and comparison purposes was meticulously determined by the board-certified radiation oncologists after comprehensive evaluation, collaboration, colleague peer review, and ultimate consensus. Thorough patient evaluation was performed considering lesion sizes, localization, association with critical structures, symptomatology, patient preferences, and contemplated outcomes of treatment. CTsimulator (GE Lightspeed RT, GE Healthcare, Chalfont St. Giles, UK) was used for treatment simulation and RT planning. Planning CT images were acquired and then sent to the contouring workstation (SimMD, GE, UK) via the network for delineation of target volumes and nearby critical structures. Target definition based on CT only and incorporated PET-CT images was evaluated with comparative analysis. RT was delivered by Synergy (Elekta, UK) linear accelerator (LINAC) with routine iutilization of Image Guided Radiation Therapy (IGRT) techniques by use of daily kilovoltage cone beam CT and electronic portal imaging.

\section{RESUltS}

RT treatment plans were generated by the precise RT planning systems at our tertiaryreferral institution. Prioritization was given for adequate encompassing of the target volume whilst protecting nearby critical structures as much as possible. Determination of ground truth target volume was performed by board-certified radiation oncologists after meticulous assessment, thorough consideration, collaboration, colleague peer review, and ultimate consensus for actual treatment and for compison purposes. RT delivery was performed by Synergy (Elekta, UK) LINAC with kilovoltage cone beam CT and electronic portal imaging verification capability. Target volume definition by CT-only imaging and by incorporated PET-CT images was assessed with comparative analysis. Ground truth target volume was found to be identical with target volume definition by incorporated PET-CT images.

\section{DISCUSSION}

NLPHL is a distinct subtype of hodgkin lymphoma with a favorable prognosis in majority of affected patients [2-5]. Active surveillance was even considered for selected patients with NLPHL with respect to indolent disease course and concerns about adverse effects of treatment [6]. Given the favorable prognosis with excellent survival of patients, improving the toxicity profile of therapy is an indispensable component of current treatment strategies. In the context of RT, there has been a trend towards irradiating limited target volumes to improve the therapeutic ratio. Cervical lymph node irradiation may be associated with radiation induced adverse effects since this region includes critical structures. LFRT may serve as a viable alternative to extended field radiotherapeutic approaches with reduced exposure of nearby critical structures. Irradiation of limited target volumes is an area of active investigation to limit radiation induced toxicities. Nevertheless, accuracy and precision in target definition is of utmost importance in the context of LFRT. In the era of artificial intelligence based applications, it is now possible to expedite several processes during the typical RT workflow such as image segmentation, image registration and reconstruction, treatment planning and verification. While RT planning is usually based on CT-simulation, incorporation of additional imaging data may significantly improve definition of target volumes for irradiation of NLPHL. Within this context, several studies have assessed multimodality imaging based target definition [13-32]. Our results support the use of multimodality imaging based target definition for radiotherapeutic management of NLPHL in the setting of LFRT, and our study may add to the growing body of evidence in the literature.

Recent years have witnessed substantial progress in radiation oncology discipline with introduction of adaptive RT approaches and state of the art treatment delivery techniques with incorporation of Image Guided Radiation Therapy (IGRT), Adaptive Radiation Therapy (ART), Breathing Adapted Radiation Therapy (BART), Intensity Modulated Radiation Therapy (IMRT), automatic segmentation techniques, molecular imaging methods, and stereotactic irradiation strategies [33-68]. In the context of RT for NLPHL, studies have addressed irradiation of limited treatment volumes to improve the toxicity profile of radiation delivery [7-12]. This strategy may result in reduced normal tissue exposure and radiation induced toxicity, however, vigilance is 
required to avoid geographic misses. Accuracy and precision in definition of target volume is a more critical aspect of radiotherapeutic management in the setting of LFRT for NLPHL.

In conclusion, multimodality imaging based target volume definition should be considered for radiotherapeutic management of NLPHL with LFRT. Further studies are needed to shed light on this issue.

\section{REFERENCES}

[1] Zhou L, Deng Y, Li N, Zheng Y, Tian T, et al. (2019) Global, regional, and national burden of Hodgkin lymphoma from 1990 to 2017: estimates from the 2017 Global Burden of Disease study. J Hematol Oncol 12: 107.

[2] Savage KJ, Mottok A, Fanale M (2016) Nodular lymphocyte-predominan Hodgkin lymphoma. Semin Hematol 53: 190-202.

[3] Eichenauer DA, Engert A (2017) Nodular lymphocytepredominant Hodgkin lym phoma: a unique disease deserving unique management. Hematology Am Soc Hematol Educ Program 2017: 324-328.

[4] Hartmann S, Eichenauer DA (2020) Nodular lymphocyte predominant Hodgkin lym phoma: pathology, clinical course and relation to T-cell/histiocyte rich large B-cell lymphoma. Pathology 52: 142-153.

[5] Alonso C, Dutta SW, Mitra N, Landsburg DJ, Zaorsky NG, et al. (2018) Adult nodular lymphocyte-predominant Hodgkin lymphoma: treatment modality utilization and survival. Cancer Med 7:1118-1126.

[6] Active surveillance for nodular lymphocytepredominant Hodgkin lymphoma. Borchmann S, Joffe E, Moskowitz CH, Zelenetz AD, Noy A, et al. (2019) Blood 133: 2121-2129.

[7] Sager O, Beyzadeoglu M, Demiral S, Dincoglan F, Gamsiz H, et al. (2020) Assessment of cardiac sparing in radiotherapeutic Management of mediastınal hodgkın lymphoma (hl) Durıng childhood and adolescence. J Surg Surgical Res 6: 106-109.

[8] SpechtL (2018) Radiotherapy for Hodgkin Lymphoma: Reducing Toxicity While Maintain ing Efficacy.Cancer J 24: 237-243.

[9] Pinnix CC, Milgrom SA, Cheah CY, Gunther JR, Ludmir EB, et al. (2019) Favorable outcomes with de-escalated radiation therapy for limited-stage nodular lymphocytepredominant Hodgkin lymphoma. Blood Adv 3: 1356-1367.

[10] Eichenauer DA, Engert A (2020) How I treat nodular lymphocyte- predominant Hodgkin lymphoma. Blood 136: 2987-2993.

[11] Spinner MA, Varma G, Advani RH (2019) Modern principles in the management of nodular lymphocyte

predominant Hodgkin lymphoma. $\mathrm{Br} J$ Haematol 184: 17-29.

[12] Nielsen K, Maraldo MV, Berthelsen AK, Loft A, de Nully Brown P, et al. (2020) Involved node radiation therapy in the combined modality treatment for early-stage Hodgkin lymphoma: Analysis of relapse location and long-term outcome. Radiother Oncol 150: 236244.

[13] Demiral S, Sager O, Dincoglan F, Uysal B, Gamsiz H, et al. (2018) Evaluation of Target Volume Determination for Single Session Stereotactic Radiosurgery (SRS) of Brain Metastases. Canc Therapy \&amp; Oncol Int J 12: 555848.

[14] Sager O, Dincoglan F, Demiral S, Gamsiz H, Uysal B, et al. (2019) Utility of Magnetic Resonance Imaging (Imaging) in Target Volume Definition for Radiosurgery of Acoustic Neuromas. Int J Cancer Clin Res 6: 119.

[15] Sager O, Dincoglan F, Demiral S, Beyzadeoglu M (2019) Evaluation of Radiosurgery Target Volume Determination for Meningiomas Based on Computed Tomography (CT) And Magnetic Resonance Imaging (MRI). Cancer Sci Res Open Access 5: $1-4$.

[16] Dincoglan F, Sager O , Demiral S, Beyzadeoglu M (2019) Multimodality Imaging for Radiosurgical Management of Arteriovenous Malformations. Asian Journal of Pharmacy, Nursing and Medical Sciences 7: 7-12.

[17] Beyzadeoglu M, Sager O, Dincoglan F, Demiral S (2019) Evaluation of Target Definition for Stereotactic Reirradiation of Recurrent Glioblastoma. Arch Can Res 7: 3.

[18] Sager O, Dincoglan F, Demiral S, Gamsiz H, Uysal B, et al. (2019) Evaluation of the Impact of Magnetic Resonance Imaging (MRI) on Gross Tumor Volume (GTV) Definition for Radiation Treatment Planning (RTP) of Inoperable High Grade Gliomas (HGGs). Concepts in Magnetic Resonance Part A 2019, Article ID 4282754.

[19] Demiral S, Sager O, Dincoglan F, Beyzadeoglu M (2019) Assessment of target definition based on Multimodality imaging for radiosurgical Management of glomus jugulare tumors (GJTs). Canc Therapy \&amp; Oncol Int J 15: 555909.

[20] Demiral S, Sager O, Dincoglan F, Beyzadeoglu M (2019) Assessment of Computed Tomography (CT) And Magnetic Resonance Imaging (MRI) Based Radiosurgery Treatment Planning for Pituitary Adenomas. Canc Therapy \&amp; Oncol Int J 13: 555857.

[21] Dincoglan F, Sager O , Demiral S, Beyzadeoglu M (2019) Incorporation of Multimodality 
[22] maging in Radiosurgery Planning for Craniopharyngiomas: An Original Article. SAJ Cancer Sci 6: 103.

[23] Sager O, Dincoglan F, Demiral S, Beyzadeoglu M (2020) Evaluation of Target Volume Determination for Irradiation of Pilocytic Astrocytomas: An Original Article. ARC Journal of Cancer Science 6: 1-5.

[24] Demiral S, Beyzadeoglu M, Dincoglan F, Sager O (2020) Evaluation of Radiosurgery Target Volume Definition for Tectal Gliomas with Incorporation of Magnetic Resonance Imaging (MRI): An Original Article. Biomedical Journal of Scientific \&amp; Technical Research (BJSTR) 27: 20543-20547.

[25] Beyzadeoglu M, Dincoglan F, Demiral S, Sager O (2020) Target Volume Determination for Precise Radiation Therapy (RT) of Central Neurocytoma: An Original Article. International Journal of Research Studies in Medical and Health Sciences 5: 29-34.

[26] Sager O, Dincoglan F, Demiral S, Beyzadeoglu M (2020) Radiosurgery Treatment Volume Determination for Brain Lymphomas with and without Incorporation of Multimodality Imaging. Journal of Medical Pharmaceutical and Allied Sciences 9: 2398- 2404.

[27] Demiral S, Beyzadeoglu M, Dincoglan F, Sager O (2020) Assessment of Target Volume Definition for Radiosurgery of Atypical Meningiomas with Multimodality Imaging. Journal of Hematology and Oncology Research 3: $14-21$.

[28] Beyzadeoglu M, Dincoglan F, Sager O, Demiral S (2020) Determination of Radiosurgery Treatment Volume for Intracranial Germ Cell Tumors (GCTS). Asian Journal of Pharmacy, Nursing and Medical Sciences 8: 18-23.

[29] Sager O, Demiral S, Dincoglan F, Beyzadeoglu M (2020) Target Volume Definition for Stereotactic Radiosurgery (SRS) Of Cerebral Cavernous Malformations (CCMs). Canc Therapy \&amp; Oncol Int J 15: 555917.

[30] Dincoglan F, Demiral S, Sager O, Beyzadeoglu M (2020) Utility of Multimodality Imaging Based Target Volume Definition for Radiosurgery of Trigeminal Neuralgia: An Original Article. Biomed J Sci \&amp; Tech Res 26: 19728-19732.

[31] Dincoglan F, Beyzadeoglu M, Demiral S, Sager O (2020) Assessment of Treatment Volume Definition for Irradiation of Spinal Ependymomas: an Original Article. ARC Journal of Cancer Science 6: 1-6.

[32] Sager O, Dincoglan F, Demiral S, Beyzadeoglu M (2020) Evaluation of Treatment Volume Determination for Irradiation of chordoma: an Original Article. International Journal of
Research Studies in Medical and Health Sciences 5 (10): 3-8

[33] Sager O, Dincoglan F, Demiral S, Beyzadeoglu M (2020) Assessment of Target Volume Definition for Irradiation of Hemangiopericytomas: An Original Article. Canc Therapy \&amp; Oncol Int J 17(2).

[34] Sager O, Dincoglan F, Demiral S, Uysal B, Gamsiz H, et al. (2020) Adaptive radiation therapy of breast cancer by repeated imaging during irradiation. World J Radiol 12: 68-75.

[35] Sager O, Dincoglan F, Demiral S, Uysal B, Gamsiz H, et al. (2019) Utility of Molecular Imaging with 2-Deoxy-2-[Fluorine-18] FluoroDGlucose Positron Emission Tomography (18F-FDG PET) for Small Cell Lung Cancer (SCLC): A Radiation Oncology Perspective. Curr Radiopharm 12: 4-10.

[36] Sager O, Dincoglan F, Demiral S, Uysal B, Gamsiz H, et al. (2019) Breathing adapted radiation therapy for leukemia relapse in the breast: A case report. World J Clin Oncol 10: 369-374.

[37] Sager O, Dincoglan F, Uysal B, Demiral S, Gamsiz H, et al. (2018) Evaluation of adaptive radiotherapy (ART) by use of replanning the tumor bed boost with repeated computed tomography (CT) simulation after whole breast irradiation (WBI) for breast cancer patients having clinically evident seroma. Jpn J Radiol 36: 401-406.

[38] Sager O, Dincoglan F, Uysal B, Demiral S, Gamsiz H, et al. (2017) Splenic Irradiation: A Concise Review of the Literature. J App Hem B1 Tran 1: 101.

[39] Sager O, Beyzadeoglu M , Dincoglan F, Demiral S, Uysal B, et al. (2015) Adaptive splenic radiotherapy for symptomatic splenomegaly management in myeloproliferativ disorders. Tumori 101: 84-90.

[40] Ozsavaş EE, Telatar Z, Dirican B , Sager O, Beyzadeoğlu M (2014) Automatic segmentation of anatomical structures from CT scans of thorax for RTP. Comput Math Methods Med 2014: 472890.

[41] Dincoglan F, Beyzadeoglu M, Sager O, Oysul K, Kahya YE, et al. (2013) Dosimetric evaluation of critical organs at risk in mastectomized left-sided breast cancer radiotherapy using breath-hold technique. Tumori 99: 76-82.

[42] Sager O, Beyzadeoglu M, Dincoglan F, Oysul K, Kahya YE, et al. (2012) Evaluation of active breathing control-moderate deep inspiration breath-hold in definitive non-small cell lung cancer radiotherapy. Neoplasma 59: 333-340.

[43] Sağer Ö, Dinçoğlan F, Gamsiz H, Demiral S, Uysal B, et al. (2012) Evaluation of the impact of integrated [18f]-fluoro-2-deoxy-D-glucose 
positron emission tomography/computed tomography imaging on staging and radiotherapy treatment volume definition of nonsmall cell lung cancer. Gulhane Med J 54: 220-227.

[44] Sager O, Beyzadeoglu M, Dincoglan F, Oysul K, Kahya YE, et al. (2012) The Role of Active Breathing Control-Moderate Deep Inspiration Breath-Hold (ABC-mDIBH) Usage in nonMastectomized Left-sided Breast Cancer Radiotherapy: A Dosimetric Evaluation UHOD - Uluslararasi Hematoloji-Onkoloji Dergisi 22: 147-155.

[45] Sager O, Beyzadeoglu M, Dincoglan F, Demiral S, Gamsiz H, et al. (2020) Multimodality management of cavernous sinus meningiomas with less extensive surgery followed by subsequent irradiation: Implications for an improved toxicity profile. $\mathrm{J}$ Surg Surgical Res 6: 056-061.

[46] Beyzadeoglu M, Sager O, Dincoglan F, Demiral S, Uysal B, et al. (2020) Single Fraction Stereotactic Radiosurgery (SRS) versus Fractionated Stereotactic Radiotherapy (FSRT) for Vestibular Schwannoma (VS). J Surg Surgical Res 6: 062-066.

[47] Dincoglan F, Beyzadeoglu M, Sager O, Demiral S, Uysal B, et al. (2020) A Concise Review of Irradiation for Temporal Bone Chemodectomas (TBC). Arch Otolaryngol Rhinol 6: 016-020.

[48] Dincoglan F, Sager O, Uysal B, Demiral S, Gamsiz H, et al. (2019) Evaluation of hypofractionated stereotactic radiotherapy (HFSRT) to the resection cavity after surgical resection of brain metastases: A single center experience. Indian J Cancer 56: 202-206.

[49] Dincoglan F, Sager O, Demiral S, Gamsiz H, Uysal B, et al. (2019) Fractionated stereotactic radiosurgery for locally recurrent brain metastases after failed stereotactic radiosurgery. Indian J Cancer 56: 151-156.

[50] Demiral S, Dincoglan F, Sager O, Uysal B, Gamsiz H, et al. (2018) Contemporary Management of Meningiomas with Radiosurgery. Int J Radiol Imaging Technol 80: 187-190.

[51] Dincoglan F, Sager O, Demiral S, Uysal B, Gamsiz H, et al. (2017) Radiosurgery for recurrent glioblastoma: A review article. Neurol Disord Therap 1: 1-5.

[52] Demiral S, Dincoglan F, Sager O, Gamsiz H, Uysal B, et al. (2016) Hypofractionated stereotactic radiotherapy (HFSRT) for who grade I anterior clinoid meningiomas (ACM). Jpn J Radiol 34: 730-737.

[53] Gamsiz H, Beyzadeoglu M, Sager O, Demiral S, Dincoglan F, et al. (2015) Evaluation of stereotactic body radiation therapy in the management of adrenal metastases from nonsmall cell lung cancer. Tumori 101: 98-103.

[54] Sager O, Dincoglan F, Beyzadeoglu M (2015) Stereotactic radiosurgery of glomus jugulare tumors: Current concepts, recent advances and future perspectives. CNS Oncol 4: 105-114.

[55] Dincoglan F, Beyzadeoglu M, Sager O, Demiral S, Gamsiz H, et al. (2015) Management of patients with recurrent glioblastoma using hypofractionated stereotactic radiotherapy. Tumori 101: 179-184.

[56] Demiral S, Beyzadeoglu M, Sager O, Dincoglan F, Gamsiz H, et al. (2014) Evaluation of Linear Accelerator (Linac)-Based Stereotactic Radiosurgery (Srs) for the Treatment of Craniopharyngiomas. UHODUluslararasi Hematoloji Onkoloji Dergisi 24(2): 123-129.

[57] Gamsiz H, Beyzadeoglu M, Sager O, Dincoglan F, Demiral S, et al. (2014) Management of pulmonary oligometastases by stereotactic body radiotherapy. Tumori 100: 179-183.

[58] Demiral S, Beyzadeoglu M, Sager O, Dincoglan F, Gamsiz H, et al. (2014) Evaluation of linear accelerator (linac)-based stereotactic radiosurgery (srs) for the treatment of craniopharyngiomas. UHOD - Uluslararasi Hematoloji-Onkoloji Dergisi 24: 123-129.

[59] Dincoglan F, Sager O, Gamsiz H, Uysal B, Demiral S, et al. (2014) Management of patients with $\geq 4$ brain metastases using stereotactic radiosurgery boost after whole brain irradiation. Tumori 100: 302-306.

[60] Sager O, Beyzadeoglu M, Dincoglan F, Gamsiz H, Demiral S, et al. (2014) Evaluation of linear accelerator-based stereotactic radiosurgery in the management of glomus jugulare tumors. Tumori 100: 184-188.

[61] Sager O, Beyzadeoglu M, Dincoglan F, Uysal B, Gamsiz H, et al. (2014) Evaluation of linear accelerator (LINAC)-based stereotactic radiosurgery (SRS) for cerebral cavernous malformations: A 15-year single-center experience. Ann Saudi Med 34: 54-58.

[62] Sager O, Beyzadeoglu M , Dincoglan F , Demiral S, Uysal B, et al. (2013) Management of vestibular schwannomas with linear accelerator-based stereotactic radiosurgery: a single center experience. Tumori 99: 617-622.

[63] Dincoglan F, Beyzadeoglu M, Sager O, Uysal B, Demiral S, et al. (2013) Evaluation of linear accelerator-based stereotactic radiosurgery in the management of meningiomas: A single center experience. J BUON 18: 717-722.

[64] Demiral S, Beyzadeoglu M, Uysal B, Oysul K, Kahya YE, et al. (2013) Evaluation of stereotactic body radiotherapy (SBRT) boost in 
the management of endometrial cancer. Neoplasma 60: 322-327.

[65] Dincoglan F, Sager O, Gamsiz H, Uysal B, Demiral S, et al. (2012) Stereotactic radiosurgery for intracranial tumors: A single center experience. Gulhane Med J 54: 190-198.

[66] Dincoglan F, Beyzadeoglu M, Sager O, Oysul K, Sirin S et al. (2012) Image-guided positioning in intracranial non-invasive stereotactic radiosurgery for the treatment of brain metastasis. Tumori 98: 630-635.

[67] Sirin S, Oysul K, Surenkok S, Sager O, Dincoglan F, et al. (2011) Linear acceleratorbased stereotactic radiosurgery in recurrent glioblastoma: A single center experience. Vojnosanit Pregl 68: 961-966.

[68] Demiral S, Sager O, Dincoglan F, Uysal B, Gamsiz H, et al. (2021) Evaluation of breathing-adapted radiation therapy for rightsided early stage breast cancer patients. Indian J Cancer 2021. doi: 10.4103/ijc.IJC_140_19. (Online ahead of print)

[69] Sager O, Dincoglan F, Demiral S, Uysal B, Gamsiz H, et al. (2021) Omission of Radiation Therapy (RT) for Metaplastic Breast Cancer (MBC): A Review Article. International Journal of Research Studies in Medical and Health Sciences 6: 10-15.

Citation: Selcuk Demiral, FerratDincoglan,Omer Sager, Murat Beyzadeoglu, Multimodality Imaging Based Target Definition of Cervical Lymph Nodes in Precise Limited Field Radiation Therapy (Lfrt) for Nodular Lymphocyte Predominant Hodgkin Lymphoma (Nlphl). ARC Journal of Cancer Science. 2020; 6(2):06-11. DOI:dx.doi.org/ 10.20431/2455-6009.0602002.

Copyright: () 2020 Authors. This is an open-access article distributed under the terms of the Creative Commons Attribution License, which permits unrestricted use, distribution, and reproduction in any medium, provided the original author and source are credited. 